\title{
(a) CASE REPORT \\ OPEN ACCESS \\ Antiresorptive-associated spontaneous fractures of both tibiae, followed by an atypical femur fracture during the sequential treatment with alendronate, denosumab then teriparatide
}

\author{
Juan Tan, ${ }^{1}$ Hiroshige Sano, ${ }^{2}$ Kenneth Poole ${ }^{3}$
}

'Department of Medicine, Royal Infirmary of Edinburgh, Edinburgh, UK

2Department of Medicine, Cambridge University, Cambridge, UK

${ }^{3}$ Metabolic Bone Disease Unit, Addenbrooke's Hospital, Cambridge, UK

Correspondence to Dr Juan Tan,

tanjuan01@gmail.com

Accepted 24 June 2019

Check for updates

(c) BMJ Publishing Group Limited 2019. Re-use permitted under CC BY-NC. No commercial re-use. See rights and permissions. Published by BMJ.

To cite: Tan J, Sano H, Poole K. BMJ Case Rep 2019:12:e229366 doi:10.1136/bcr-2019229366

\section{SUMMARY}

A 35-year-old man with juvenile idiopathic arthritis since childhood presented with bilateral atypical tibial fractures, followed by a later, single atypical fracture of the femur. The fractures were associated with 6 years of oral alendronate treatment immediately followed by subcutaneous denosumab therapy and later teriparatide therapy for osteoporosis. Atypical fractures are known to occur in the femur following bisphosphonate therapy; however, there are only a few documented cases of atypical fractures in the tibia. Our case highlights a rare but serious complication of a commonly prescribed antiresorptive agent. It also shows that teriparatide, while helpful in increasing bone mass, does not fully prevent the development of atypical fractures. Careful investigation should be considered in patients on long-term antiresorptive therapy presenting with bony tenderness to exclude an atypical fracture.

\section{BACKGROUND}

Juvenile idiopathic arthritis is associated with tibial stress fractures in children, ${ }^{1}$ but here we present a challenging case in an adult, where antiresorptive therapy and underlying inflammatory disease may have been involved in the pathogenesis of multiple lower limb atypical fractures. Bisphosphonates are widely prescribed to prevent and treat osteoporosis. They have a good safety profile and are highly effective in increasing bone mass and density, thereby reducing fragility fracture risk. ${ }^{23}$ As analogues of inorganic pyrophosphate, bisphosphonates readily integrate at bone surfaces and induce osteoclast apoptosis, thereby suppressing bone resorption and increasing bone mass. Denosumab is a monoclonal antibody that binds RANK-Ligand, thereby inhibiting the recruitment and formation of osteoclasts, increasing bone mass and reducing fragility fractures. Both are in the class of 'antiresorptive drugs', having effects on both resorption and subsequent bone formation. Paradoxically, long-term antiresorptive use might impair bone remodelling and repair, resulting in the progressive accumulation of microdamage and increasing the risk of low turnover 'atypical' stress fractures. ${ }^{4-7}$ As the primary weight-bearing bone during bipedal walking, the upper mid-femur appears to be particularly susceptible to developing atypical stress fractures. ${ }^{8-13}$
Fractures in other long bones such as the tibia have only rarely been reported. ${ }^{14-18}$ We describe a case of a 35-year-old man with juvenile idiopathic arthritis since childhood who presented with bilateral atypical tibial fractures, followed by a later, single atypical fracture of the femur. The fractures were associated with 6 years of oral alendronate treatment immediately followed by subcutaneous denosumab therapy and later teriparatide therapy for osteoporosis.

\section{CASE PRESENTATION}

A 35-year-old Caucasian man with a history of glucocorticoid-induced osteoporosis secondary to juvenile and continuing adult severe inflammatory arthritis took alendronic acid (70mg) weekly for 6 years continuously. He presented with a symptomatic left anterior tibial stress fracture associated with slight anterior bowing of his tibia and evidence of endosteal oedema on MRI (figure 1). This was managed conservatively, but he presented 7 months later with worsening acute pain in his left leg while seated. On examination, he had bony tenderness of the left mid-distal tibia with difficulty weightbearing. There was no history of falls or local trauma. Other relevant medications included fortnightly adalimumab $(40 \mathrm{mg})$, as well as one time per day leflunomide $(20 \mathrm{mg})$, prednisolone $(15 \mathrm{mg})$ and etodolac $(600 \mathrm{mg})$. There was no history of cigarette smoking, no relevant alcohol intake and his body mass index (BMI) was below 25. He was ambulant without aids prior to his stress fracture but walked with an antalgic gait due to severe arthritis affecting his ankles and knees bilaterally.

At presentation, the plain X-ray revealed an incomplete, non-displaced short oblique fracture in the anterior middle-third of the left tibial diaphysis associated at the point of maximal anterior bowing of the tibia, that is, in a region subjected to high tensile forces during gait (figure 2). Bone mineral density (BMD) T-scores using dual-energy X-ray absorptiometry (DEXA) were -3.0 at the neck of femur and -3.1 at the lumbar spine (a T-score of $<2.5$ is a diagnosis of osteoporosis). He was fitted with a fibreglass cast and further conservative management was tried. Before coming under our care, his osteoporosis therapy was switched to subcutaneous denosumab $60 \mathrm{mg}$ 6-monthly due to 


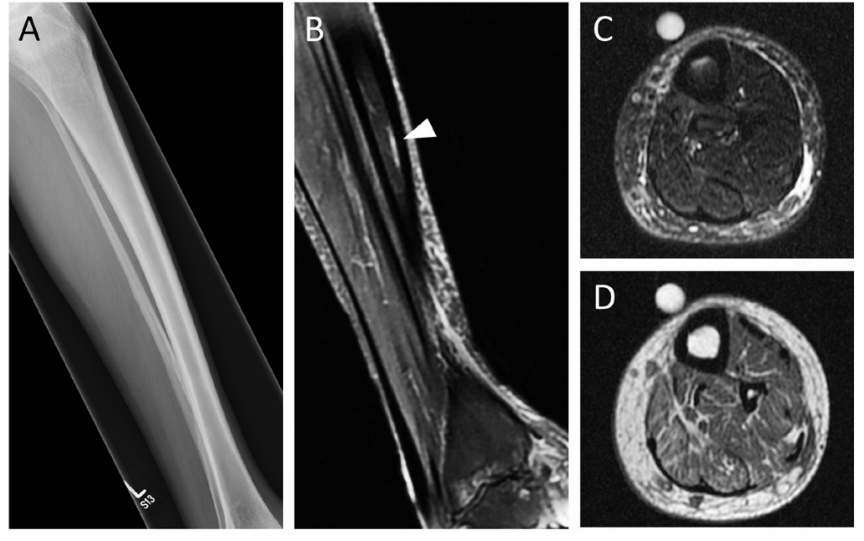

Figure 1 Lateral tibial X-ray obtained at the first visit (A). Sagittal fat-supressed proton density-weighted image showed endosteal oedema (arrowhead) (B). Axial fat-suppressed fast spin echo (C) and T1-weighted image (D) did not show focal cortical thickening. Markers $(C, D)$ showed the region of prodromal pain. High intensity $(B, C)$ and low intensity (D) signals in bone marrow represent endosteal oedema.

concerns that alendronic acid may have interfered with fracture healing. A time frame of the events following this fracture is available in figure 3 .

He continued to exhibit poor fracture healing over a year later. $\mathrm{X}$-rays showed that the fracture line was still visible, with ongoing pain and no evidence of bone union. Teriparatide injections were commenced. Adalimumab was increased to $40 \mathrm{mg}$ weekly due to significant joint pain from active arthritis. Etodolac was stopped. Two months later, he developed a strikingly similar atypical fracture, this time in his right tibia (figure 2). Both tibiae were fixed with anterior tibial plates and screws.

He presented again 4 months postrepair with spontaneous bilateral periprosthetic transverse fractures that occurred suddenly while walking up the stairs at work. The tibial plates were removed, and the tibiae were fixed with intramedullary nails instead. A subsequent review showed a good postoperative
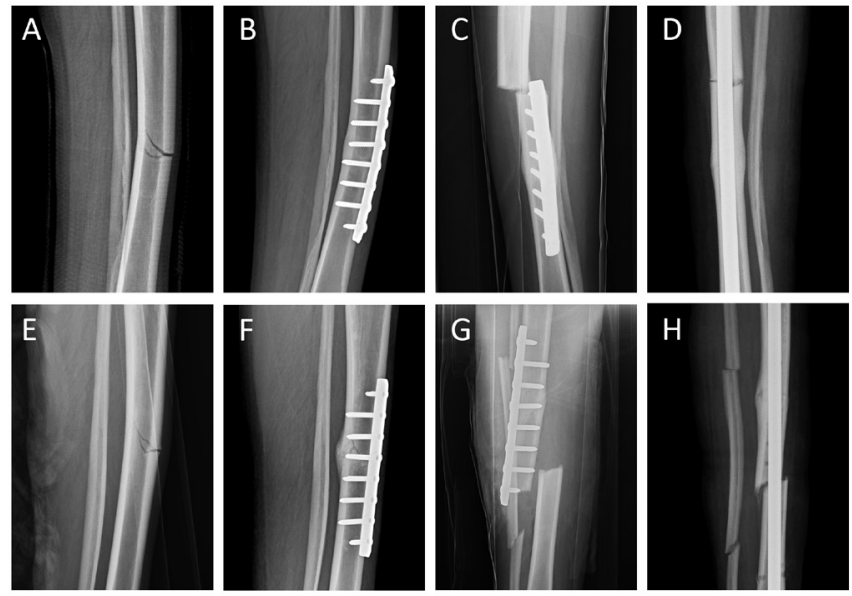

Figure 2 Time course of an atypical fracture of the left $(A-D)$ and right $(E-H)$ tibia in lateral $(A, B, E, F)$ and anteroposterior $(C, D, G, H)$ views. $(A, E)$ Similar mid-shaft fractures across the anterior cortex of the left and right tibial diaphysis. The fracture line originated transversely and became oblique as it progressed posteriorly across the tibia; $(\mathrm{B}, \mathrm{F})$ fractures 1 month after repair with tibial plates; $(C, G)$ subsequent periprosthetic fractures; $(D, H)$ final fracture repair with medullary nails.
Months Since Initial Presentation

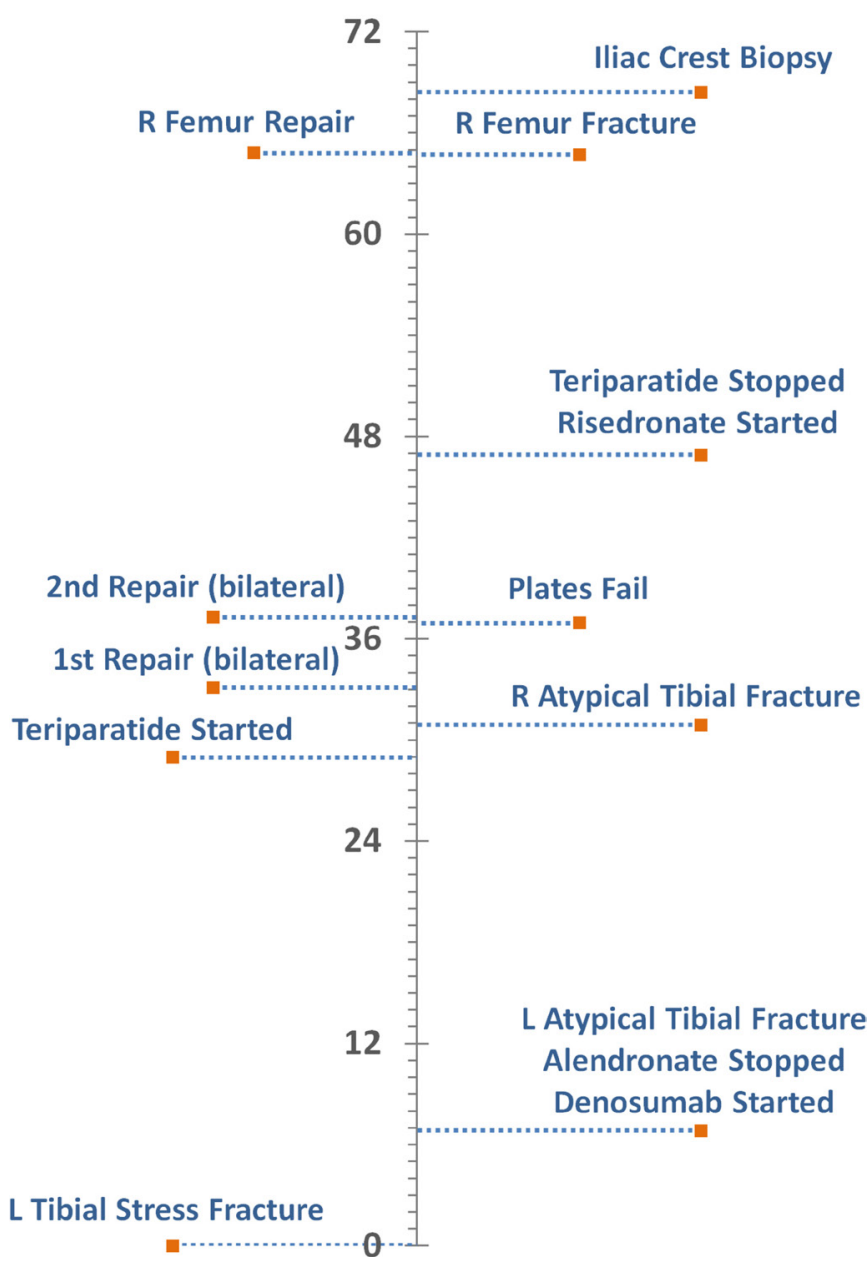

Figure 3 Timeline of events following initial presentation with left anterior tibial stress fracture.

result with the anterior bowing of his tibiae corrected after nailing. Adalimumab was switched to tocilizumab due to worsening arthritis, but teriparatide injections were stopped after 18 months as he developed recurrent infections around the injection site. A DEXA scan demonstrated that his Z-scores had improved to -2.3 at the lumbar spine but only to -2.8 at the femoral neck. He was commenced on risedronate $35 \mathrm{mg}$ once weekly to maintain BMD gains induced by teriparatide.

One and half years later, he sustained a right femoral fracture (figure 4) associated with, but not necessarily caused by, a fall from standing height. X-rays showed a short oblique fracture at the proximal femoral diaphysis with cortical beaking. The fracture was treated with intramedullary nail fixation. A transiliac crest bone biopsy was subsequently taken following double tetracycline labelling to assess bone turnover. There was no evidence of malignancy, osteomalacia nor absent populations of osteoclasts. Bone volume over total volume was $17.2 \%$ (normal range: $16.4 \%-24.8 \%$ ). Tetracycline labelling showed normal mineralisation and high bone turnover, with no suggestion of oversuppression (figure 5).

\section{OUTCOME AND FOLLOW-UP}

Our patient has since recovered well from his fractures and continues to receive regular follow-up with his rheumatologist. 

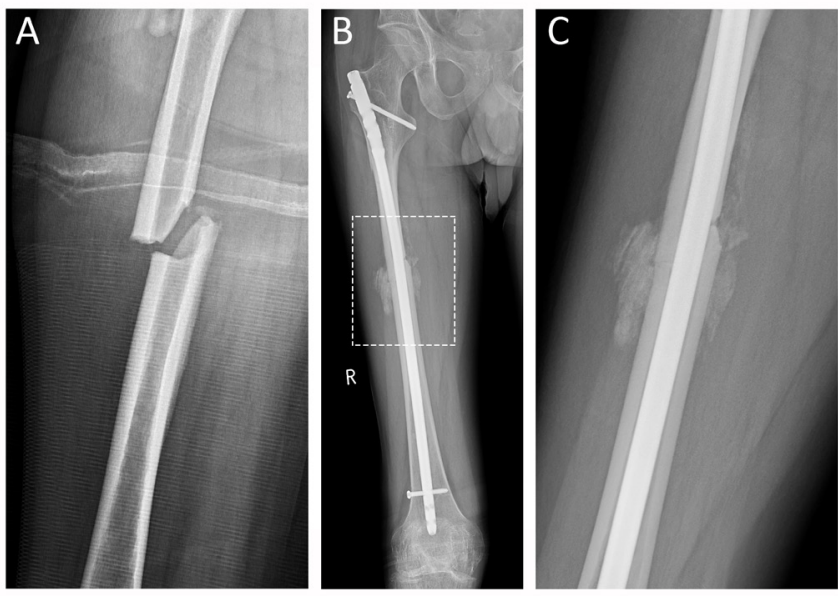

Figure 4 Anteroposterior radiographs of an atypical insufficiency fracture of the right proximal femur. There is a transverse fracture line that becomes oblique as it progresses laterally across the femoral cortex with a medial spike (A). X-ray 2 months later after intramedullary nailing (B). Highly magnified area (C) showing evidence of periosteal and endosteal callus reaction.

\section{DISCUSSION}

There is a growing body of evidence linking long-term bisphosphonate use with atypical femoral fractures. Although initial registry studies found no correlation between bisphosphonate use and the rate of subtrochanteric or femoral shaft fractures, ${ }^{19-21}$ such studies have been criticised for overrelying on diagnostic codes, which fail to adequately distinguish atypical femoral fractures from other fractures. ${ }^{22} 23$ Conversely, most studies utilising radiographic data have demonstrated a strong association between bisphosphonates and atypical femoral fractures. $^{22-24}$ A subsequent meta-analysis assessing data from both registry and radiographic studies has also shown an increased risk of subtrochanteric, femoral shaft and atypical femoral fractures with bisphosphonate usage. ${ }^{25}$

Atypical insufficiency fractures of the tibia, on the contrary, are much less common. There are only a few case reports available which describe insufficiency fractures occurring in the tibial diaphysis ${ }^{14-16}$ and metaphysis ${ }^{17} 18$ of patients on long-term bisphosphonate therapy (table 1). The American Society for Bone and Mineral Research (ASBMR) has specific guidelines, which delineate the criteria for atypical insufficiency fractures. ${ }^{26} 27$
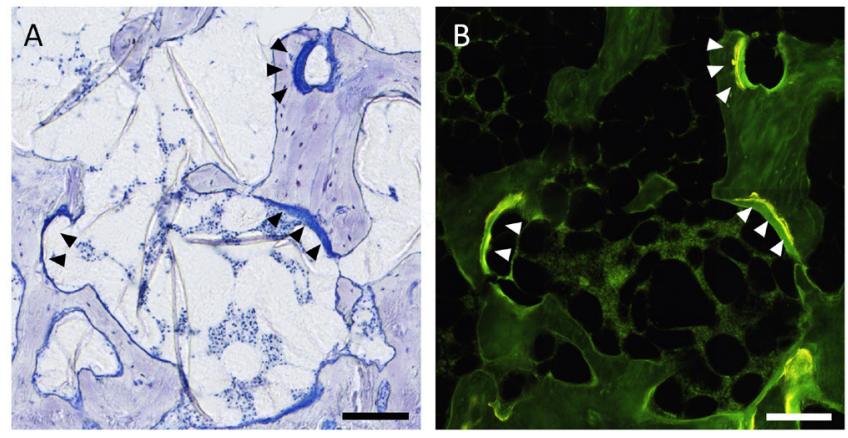

Figure 5 (A) Light micrograph of a section stained with toluidine blue from a transiliac bone biopsy taken after double tetracycline labelling. Osteoid seams were detected on trabeculae (arrow heads). (B) Fluorescence micrograph showing tetracycline-labelled bone surfaces corresponding with osteoid surfaces (arrow heads). Scale bars: $150 \mu \mathrm{m}$.
However, this definition is strictly limited to femoral fractures and is not designed for fractures in alternative sites. Save for its location in the distal tibia, our case matches all major and multiple minor ASBMR criteria for atypical fractures. Key features include presenting with bilateral transverse, non-comminuted tibial fractures following no trauma, with delayed fracture healing and prodromal pain for several months leading up to the fracture.

The pathogenesis of atypical tibial fractures is unclear. In our patient, abnormal anterior tibial bowing could have led to altered biomechanical forces across the tibia, resulting in the development of microfractures along the anterior cortex. These were mild bilateral shape abnormalities, which might have been caused by the effects of juvenile arthritis on bone development rather than a true deformity (such as congenital pseudoarthrosis). It has been hypothesised that micromovements within a fracture can inhibit cellular remodelling and that osteoclast-mediated widening of the fracture gap is required before bone formation can occur. ${ }^{23}$ Excessive osteoclast inhibition through long-term bisphosphonate and antiresorptive therapy could therefore predispose to the development of atypical insufficiency fractures. The duration of bisphosphonate usage has been strongly correlated with the risk of atypical femoral fractures. ${ }^{28} 29$ In a recent large cohort study, it was found that patients on bisphosphonates for over 8 years were more than 40 times more likely to develop atypical femoral fractures compared with patients with less than 1 year of usage. ${ }^{30}$ However, care should be taken when extrapolating these findings to tibial fractures. There is no current consensus on how to mitigate the risk of atypical fractures in long-term treated patients such as ours, who have a very substantial burden of severe osteoporotic disease, ongoing moderate steroid usage and in whom most guidelines would advocate continual treatment rather than a bisphosphonate break.

Other risk factors that may have contributed to his atypical fractures include the corticosteroid use itself and inflammatory arthritis. Denosumab, while certainly useful in the treatment of osteoporosis and prevention of fragility fractures, might in his case have led to accumulation of microfractures through blocking RANK-Ligand. Denosumab-associated atypical fractures following treatment for osteoporosis have been previously reported ${ }^{31-33}$ although these cases are uncommon. The extent to which any or all of these risk factors may have contributed to the development of his fractures remains uncertain.

The other point of interest in our case is the development of an atypical femoral fracture after our patient was started on risedronate treatment following completion of teriparatide therapy. Teriparatide has been shown to be effective in improving bone mass and reducing fracture healing time in atypical fractures secondary to bisphosphonate usage. ${ }^{34-36}$ However, similar cases of atypical femoral fractures occurring with the recommencement of antiresorptive agents following teriparatide therapy have previously been reported. ${ }^{37}{ }^{38}$ It has been suggested that teriparatide may not be fully able to counteract the long-term effects of bisphosphonates on bone or that the reintroduction of antiresorptives could also be implicated in the recurrence of atypical fractures. ${ }^{37}$ Histomorphometry of our patient's iliac crest biopsy has shown no evidence of oversuppression of bone turnover to account for his atypical fracture. This runs contrary to several reports that have demonstrated markedly reduced bone turnover in bisphosphonate-treated patients suffering from atypical fractures. ${ }^{5} 6816$ There has been a case report that has shown no evidence of adynamic bone in a patient with atypical femoral fractures; however, the biopsy specimen was taken from near the fracture 
Table 1 Current published case reports on atypical tibial fractures associated with long-term bisphosphonate/antiresorptive use

\begin{tabular}{|c|c|c|c|c|c|}
\hline Case report & Age (in years)/sex & Diagnosis & Antiresorptive agent (duration) & Fracture site & Management \\
\hline Bissonnette et $a l^{14}$ & $77, \mathrm{~F}$ & Postmenopausal osteoporosis & Zoledronate (4 years) & Left tibial diaphyseal fracture & $\begin{array}{l}\text { Intramedullary nail } \\
\text { fixation }\end{array}$ \\
\hline Breglia and Carter ${ }^{15}$ & $48, F$ & $\begin{array}{l}\text { Rheumatoid arthritis, } \\
\text { glucocorticoid-induced } \\
\text { osteoporosis }\end{array}$ & Alendronate (12 years) & Left tibial diaphyseal fracture & Conservative \\
\hline Odvina et $a^{16}$ & $54, F$ & Postmenopausal osteopenia & Risedronate (3 years) & Right pelvis and right tibia & Not specified \\
\hline Imbuldeniya et al ${ }^{17}$ & $76, F$ & $\begin{array}{l}\text { Rheumatoid arthritis, } \\
\text { osteomalacia, glucocorticoid- } \\
\text { induced osteoporosis }\end{array}$ & $\begin{array}{l}\text { Alendronate ( } 3 \text { years), pamidronate } \\
\text { (6 years) }\end{array}$ & $\begin{array}{l}\text { Bilateral proximal tibial } \\
\text { metaphyseal fractures }\end{array}$ & Conservative \\
\hline Schimpf et al ${ }^{18}$ & $76, F$ & $\begin{array}{l}\text { Rheumatoid arthritis, } \\
\text { glucocorticoid-induced } \\
\text { osteoporosis }\end{array}$ & $\begin{array}{l}\text { Risedronate ( } 5 \text { years), strontium } \\
\text { ranelate ( } 2 \text { years), zoledronate ( } 4 \\
\text { years), denosumab ( } 2 \text { years) }\end{array}$ & $\begin{array}{l}\text { Bilateral distal tibial } \\
\text { metaphyseal fractures }\end{array}$ & Tibial plates+screws \\
\hline
\end{tabular}

site, which may have locally elevated bone turnover rates. ${ }^{39}$ The high rates of bone turnover in our case are most likely due to the effects of prior teriparatide therapy on stimulating bone formation, although it appears that this does not prevent the formation of atypical fractures.

In summary, atypical fractures potentially associated with antiresorptive therapy can occur in weight-bearing long bones other than the femur. Moreover, teriparatide usage does not prevent the development of atypical fractures. Given the low incidence of bisphosphonate-related atypical fractures and good evidence that benefits outweigh risks if appropriate 'bisphosphonate holidays' are taken, findings from this case should not be extrapolated to other patients taking antiresorptives beyond 5 years. However, bony femoral or tibial tenderness in a patient on long-term antiresorptive treatment should prompt careful investigation to exclude an atypical fracture. Current guidelines are unclear about the optimal treatment of severe osteoporosis after an atypical fracture, and new strategies may be required to prevent ongoing harm in patients such as this.

\section{Learning points}

- Atypical fractures in the tibia can be a potential complication of long-term antiresorptive therapy.

- Teriparatide, while helpful in increasing bone mass, does not fully prevent the development of an atypical fracture.

- Careful investigation should be considered in patients on long-term antiresorptive agents presenting with bony tenderness to exclude an atypical fracture.

- Appropriate 'bisphosphonate holidays' should be taken to minimise the risk of developing atypical fractures.

Acknowledgements The authors are grateful to Dr Linda Skingle for help with the preparation of the histomorphometry samples. The authors also acknowledge the support of the NIHR Cambridge BRC and the Addenbrooke's Charitable Trust.

Contributors The case was supervised by KP. The patient was under the care of KP. The report was written by JT and HS.

Funding The authors have not declared a specific grant for this research from any funding agency in the public, commercial or not-for-profit sectors.

Competing interests None declared.

\section{Patient consent for publication Obtained.}

Provenance and peer review Not commissioned; externally peer reviewed.

Open access This is an open access article distributed in accordance with the Creative Commons Attribution Non Commercial (CC BY-NC 4.0) license, which permits others to distribute, remix, adapt, build upon this work non-commercially, and license their derivative works on different terms, provided the original work is properly cited and the use is non-commercial. See: http://creativecommons.org/ licenses/by-nc/4.0/

\section{REFERENCES}

1 Kuemmerle-Deschner JB, Dammann F, Niethammer D, et al. Stress fractures: diagnostic pitfalls in juvenile idiopathic arthritis. Rheumatology 2001;40:1313-4.

2 Black DM, Cummings SR, Karpf DB, et al. Randomised trial of effect of alendronate on risk of fracture in women with existing vertebral fractures. Fracture Intervention Trial Research Group. Lancet 1996;348:1535-41.

3 Papapoulos SE. Chapter 49. Bisphosphonates for Postmenopausal Osteoporosis. Primer on the metabolic bone diseases and disorders of mineral metabolism: John Wiley \& Sons, Inc, 2008:237-41.

4 Mashiba T, Hirano T, Turner $\mathrm{CH}$, et al. Suppressed bone turnover by bisphosphonates increases microdamage accumulation and reduces some biomechanical properties in dog rib. J Bone Miner Res 2000;15:613-20.

5 Odvina CV, Zerwekh JE, Rao DS, et al. Severely suppressed bone turnover: a potential complication of alendronate therapy. J Clin Endocrinol Metab 2005;90:1294-301.

6 Visekruna M, Wilson D, McKiernan FE. Severely suppressed bone turnover and atypical skeletal fragility. J Clin Endocrinol Metab 2008;93:2948-52.

7 Watts NB, Diab DL. Long-term use of bisphosphonates in osteoporosis. J Clin Endocrinol Metab 2010;95:1555-65.

8 Armamento-Villareal R, Napoli N, Panwar V, et al. Suppressed bone turnover during alendronate therapy for high-turnover osteoporosis. N Engl J Med 2006;355:2048-50.

9 Butler I, Tipping B, Bhaga R. Atypical femoral fractures. Journal of Endocrinology, Metabolism and Diabetes of South Africa 2013;18:125-7.

10 Chang ST, Tenforde AS, Grimsrud CD, et al. Atypical femur fractures among breast cancer and multiple myeloma patients receiving intravenous bisphosphonate therapy. Bone 2012;51:524-7

11 Girgis CM, Sher D, Seibel MJ. Atypical femoral fractures and bisphosphonate use. N Engl J Med 2010;362:1848-9.

12 Giusti A, Hamdy NA, Papapoulos SE. Atypical fractures of the femur and bisphosphonate therapy: a systematic review of case/case series studies. Bone 2010;47:169-80.

13 Kwek EB, Goh SK, Koh JS, et al. An emerging pattern of subtrochanteric stress fractures: a long-term complication of alendronate therapy? Injury 2008;39:224-31.

14 Bissonnette L, April PM, Dumais R, et al. Atypical fracture of the tibial diaphysis associated with bisphosphonate therapy: a case report. Bone 2013;56:406-9.

15 Breglia MD, Carter JD. Atypical insufficiency fracture of the tibia associated with longterm bisphosphonate therapy. J Clin Rheumatol 2010;16:76-8.

16 Odvina CV, Levy S, Rao S, et al. Unusual mid-shaft fractures during long-term bisphosphonate therapy. Clin Endocrinol 2010;72:161-8.

17 Imbuldeniya AM, Jiwa N, Murphy JP. Bilateral atypical insufficiency fractures of the proximal tibia and a unilateral distal femoral fracture associated with long-term intravenous bisphosphonate therapy: a case report. J Med Case Rep 2012;6:50

18 Schimpf R, Siekmann H, Bauer C, et al. Atypische distale Tibiaschaftfrakturen bei liegenden KTEP beidseits unter antiresorptiver Therapie. Der Orthopäde 2018:47:688-91.

19 Black DM, Kelly MP, Genant HK, et al. Bisphosphonates and fractures of the subtrochanteric or diaphyseal femur. N Engl J Med 2010;362:1761-71.

20 Vestergaard P, Schwartz F, Rejnmark L, et al. Risk of femoral shaft and subtrochanteric fractures among users of bisphosphonates and raloxifene. Osteoporos Int 2011;22:993-1001.

21 Abrahamsen B, Eiken P, Eastell R. Subtrochanteric and diaphyseal femur fractures in patients treated with alendronate: a register-based national cohort study. J Bone Miner Res 2009;24:1095-102 
22 Kharwadkar N, Mayne B, Lawrence JE, et al. Bisphosphonates and atypical subtrochanteric fractures of the femur. Bone Joint Res 2017;6:144-53.

23 Epidemiology SJ. radiology and histology of atypical femoral fractures. Acta Orthop Supp/ 2013;84:1-26.

24 Abrahamsen B. Atypical femur fractures: refining the clinical picture. J Bone Miner Res 2012;27:975-6.

25 Gedmintas L, Solomon DH, Kim SC. Bisphosphonates and risk of subtrochanteric, femoral shaft, and atypical femur fracture: a systematic review and meta-analysis. J Bone Miner Res 2013:28:1729-37.

26 Shane E, Burr D, Abrahamsen B, et al. Atypical subtrochanteric and diaphyseal femora fractures: second report of a task force of the American Society for Bone and Mineral Research. J Bone Miner Res 2014;29:1-23.

27 Shane E, Burr D, Ebeling PR, et al. Atypical subtrochanteric and diaphyseal femoral fractures: report of a task force of the American Society for Bone and Mineral Research. J Bone Miner Res 2010;25:2267-94.

28 Jc L, Grimsrud CD, Ott SM, et al. Incidence of Complete Atypical Femur Fracture among Women with Oral Bisphosphonate Exposure in an Integrated Healthcare System. Proceedings of the American Society of Bone and Mineral Research Annual Meeting 2018. Orlando, Florida, USA: ASBMR, 2018.

29 Dell RM, Adams AL, Greene DF, et al. Incidence of atypical nontraumatic diaphyseal fractures of the femur. J Bone Miner Res 2012;27:2544-50.

30 Geiger EJ, Black DM, Bh L, et al. Risk Factors for Atypical Femur Fractures in a Large, Prospective Cohort Study: A Multivariable Analysis from the Southern California Osteoporosis Cohort Study (SOCS). Proceedings of the American Society of Bone and Mineral Research Annual Meeting 2018. Orlando, Florida, USA: ASBMR, 2018.

31 Drampalos E, Skarpas G, Barbounakis N, et al. Atypical femoral fractures bilaterally in a patient receiving denosumab. Acta Orthop 2014;85:3-5.

32 Thompson RN, Armstrong CL, Heyburn G. Bilateral atypical femoral fractures in a patient prescribed denosumab - a case report. Bone 2014:61:44-7.

33 Schilcher J, Aspenberg P. Atypical fracture of the femur in a patient using denosumab-a case report. Acta Orthop 2014;85:6-7.

34 Im Gl, Lee SH. Effect of Teriparatide on Healing of Atypical Femoral Fractures: A Systemic Review. J Bone Metab 2015;22:183-9.

35 Aspenberg P, Genant HK, Johansson T, et al. Teriparatide for acceleration of fracture repair in humans: a prospective, randomized, double-blind study of 102 postmenopausal women with distal radial fractures. J Bone Miner Res 2010;25:404-14.

36 Miyakoshi N, Aizawa T, Sasaki S, et al. Healing of bisphosphonate-associated atypical femoral fractures in patients with osteoporosis: a comparison between treatment with and without teriparatide. J Bone Miner Metab 2015;33:553-9.

37 Nguyen $\mathrm{HH}$, Milat F, Ebeling PR. A new contralateral atypical femoral fracture despite sequential therapy with teriparatide and strontium ranelate. Bone Rep 2017:6:34-7.

38 Ramchand SK, Chiang CY, Zebaze RM, et al. Recurrence of bilateral atypical femoral fractures associated with the sequential use of teriparatide and denosumab: a case report. Osteoporos Int 2016;27:821-5.

39 Jamal SA, Dion N, Ste-Marie LG. Atypical femoral fractures and bone turnover. N Engl J Med 2011:365:1261-2

Copyright 2019 BMJ Publishing Group. All rights reserved. For permission to reuse any of this content visit

https://www.bmj.com/company/products-services/rights-and-licensing/permissions/

BMJ Case Report Fellows may re-use this article for personal use and teaching without any further permission.

Become a Fellow of BMJ Case Reports today and you can:

- Submit as many cases as you like

- Enjoy fast sympathetic peer review and rapid publication of accepted articles

- Access all the published articles

Re-use any of the published material for personal use and teaching without further permission

Customer Service

If you have any further queries about your subscription, please contact our customer services team on +44 (0) 2071111105 or via email at support@bmj.com.

Visit casereports.bmj.com for more articles like this and to become a Fellow 